\title{
Early Proximal Junctional Failure in Patients with Preoperative Sagittal Imbalance
}

\author{
Micah W. Smith ${ }^{1}$ Prokopis Annis ${ }^{1} \quad$ Brandon D. Lawrence $^{1} \quad$ Michael D. Daubs $^{2} \quad$ Darrel S. Brodke ${ }^{1}$ \\ ${ }^{1}$ Department of Orthopaedic Surgery, University of Utah, Salt Lake \\ City, Utah, United States \\ 2 UCLA Spine Center, Santa Monica, California, United States \\ Address for correspondence Darrel S. Brodke, MD, Department of \\ Orthopaedic Surgery, University of Utah, 590 Wakara Way, Salt Lake \\ City, UT 84108, United States (e-mail: wabashspine@gmail.com).
}

Evid Based Spine Care J 2013;4:163-164.

\begin{abstract}
Keywords

- adult spinal deformity

- proximal junctional failure

- spine surgery

- sagittal balance

Study Type Retrospective review.

Introduction Sagittal imbalance has been associated with lower health-related quality of life outcomes, and restoration of imbalance is associated with improved outcomes. ${ }^{1-3}$ The long constructs used in adult spinal deformity have potential consequences such as proximal junctional kyphosis (PJK). Clinically, the development of PJK may not be as important as failure of the construct or vertebrae at the proximal end. As PJK does not lead to worse clinical outcomes, ${ }^{4,5}$ we define the term early proximal junctional failure (EPJF) as fracture, implant failure, or myelopathy due to stenosis at the upper instrumental vertebra (UIV) or UIV +1 within 6 months of surgery.

Objective The purpose of this study is to report the incidence of EPJF in patients who are sagittally imbalanced preoperatively and to identify risk factors postoperatively that correlate with EPJF using commonly reported sagittal balance parameters.

Methods We reviewed 197 patients with preoperative sagittal imbalance by at least one of the following: sagittal vertical axis more than $5 \mathrm{~cm}$, global sagittal alignment more than 45 degrees, pelvic incidence-lumbar lordosis more than 10 degrees, or spine-sacral angle less than 120 degrees. Radiographic measurements also included proximal junctional angle, thoracic kyphosis, lumbar lordosis, pelvic parameters, and sagittal balance parameters/formulas, as well as UIV angle, UIV spinosacral angle, and UIV plumb line to assess as potential risk factors. EPJF incidence was calculated postoperatively for each of the accepted sagittal balance parameters/formulas.

Results EPJF was observed in 49 of 197 patients (25\%) with preoperative sagittal imbalance and was more common in fusions with UIV in the lower thoracic spine (TS) $(35 \%)$ than in those with UIV in the upper TS $(10 \%)$ or lumbar $(25 \%)(p=0.007)$. Of the 49 EPJF patients, 16 patients (33\%) required revision surgery within the first year, for an overall early revision rate of $8 \%$. The incidence of EPJF was no different in patients with or without postoperative sagittal balance. No parameter/formula was more sensitive than another in predicting EPJF.

Conclusions The incidence of EPJF (25\%) is greater in this sagittally imbalanced group than previously reported for adult deformity patients, occurring most often when the UIV is in the lower TS. Sagittal balance correction was not correlated with change in incidence of EPJF. Despite the high incidence, the early revision rate within the first year is low.
\end{abstract}

received

June 17, 2013

accepted

July 18, 2013 (c) 2013 Georg Thieme Verlag KG Stuttgart · New York
DOI http://dx.doi.org/ 10.1055/s-0033-1357366. ISSN 1663-7976. 
164 EPJF in Patients with Preoperative Sagittal Imbalance Smith et al.

\section{Disclosures}

Regarding this study, no author received any funding nor is there any conflict of interest.

\section{References}

1 Mac-Thiong J-M, Transfeldt EE, Mehbod AA, et al. Can c7 plumbline and gravity line predict health related quality of life in adult scoliosis? Spine (Phila PA 1976) 2009;34(15):E519-E527

2 Glassman SD, Berven S, Bridwell K, Horton W, Dimar JR. Correlation of radiographic parameters and clinical symptoms in adult scoliosis. Spine (Phila PA 1976) 2005;30(6):682-688
3 Glassman SD, Bridwell K, Dimar JR, Horton W, Berven S, Schwab F. The impact of positive sagittal balance in adult spinal deformity. Spine(Phila PA 1976) 2005;30(18):2024-2029

4 Yagi M, Akilah KB, Boachie-Adjei O. Incidence, risk factors and classification of proximal junctional kyphosis: surgical outcomes review of adult idiopathic scoliosis. Spine (Phila PA 1976) 2011; 36(1):E60-E68

5 Glattes RC, Bridwell KH, Lenke LG, Kim YJ, Rinella A, Edwards C II. Proximal junctional kyphosis in adult spinal deformity following long instrumented posterior spinal fusion: incidence, outcomes, and risk factor analysis. Spine (Phila PA 1976) 2005;30(14): 1643-1649 